Revista de Derecho YACHAQ N. ${ }^{\circ} 11$

Centro de Investigación de los Estudiantes de Derecho (CIED)

Universidad Nacional de San Antonio Abad del Cusco

ISSN: 2707-1197 (en linea)

ISSN: 1817-597X (impresa)

Fecha de recepción: 24/05/20

Fecha de aceptación: 20/07/20

[pp. 183-199]

\title{
Reflexiones en torno al proceso judicial por infracciones aduaneras en Uruguay
}

\author{
Thoughts on the judicial process \\ for customs offences in Uruguay
}

\author{
Andrés Varela ${ }^{[*]}$
}

\begin{abstract}
Resumen: el presente artículo pretende hacer foco en algunas cuestiones del proceso judicial por infracciones aduaneras en Uruguay, en particular, se reflexiona en torno al contenido del Derecho Aduanero y a las infracciones aduaneras. Se analiza el contenido, necesidad y finalidad del Proceso Aduanero por Infracciones Aduaneras editado por el Código Aduanero de la República Oriental del Uruguay. Asimismo, mediante un análisis de las características de su contenido, se proponen recalificaciones a su pretendida ubicación como Proceso Civil, reconociéndolo como Proceso "Aduanero", y con ello, como una categoría dentro de los Procesos Sancionatorios. Se analiza el objeto del Proceso Aduanero y su vinculación con la pretensión, para determinar que el mismo se forma progresivamente hasta su fijación en la Demanda Acusación Fiscal.
\end{abstract}

Palabras claves: derecho aduanero, Infraccional aduanero, Proceso de Conocimiento por Infracciones Aduaneras, Código Aduanero de la República Oriental del Uruguay.

Abstract: this paper focuses on some issues regarding the judicial process for customs offenses in Uruguay, particularly, it reflexes about the content of Customs Law and cus-

[*] Doctor en Derecho y Ciencias Sociales, Facultad de Derecho, Universidad de la República (Uruguay).

Profesor Adjunto (U.R.), encargado de los Cursos de Derecho Aduanero (Abogacía), y de Régimen Jurídico del Comercio Exterior I: Derecho Aduanero y de Práctica del Comercio Exterior (ambos en la Licenciatura de Relaciones Internacionales) en la Facultad de Derecho, Universidad de la República (Uruguay).

Docente encargado de los Cursos de «Actualización y Profundización en Derecho Aduanero», e «Introducción al Derecho Aduanero", en la Escuela de Posgrado, Facultad de Derecho, Universidad de la República (Uruguay). Coordinador General y expositor en la Primera a Sexta Jornada Académica de Derecho Aduanero» (20142019). Disertante en diversos eventos académicos sobre Derecho Aduanero.

Miembro del Instituto de Finanzas Públicas (Facultad de Derecho, UdelaR) y del Instituto Uruguayo de Derecho Aduanero. Abogado. Correo electrónico: drvarela@adinet.com.uy 
toms offenses. The content, necessity and purpose of the customs offenses judicial process ruled by the Uruguayan customs code are analyzed. Also, through the assessment of the characteristics of the process, rectifications to its pretended ubication like a civil process are proposed, re-qualifying it as the "customs" process, falling as a category within the sanctionatory process. There is also an analysis of the object of the process, assessing its relationship with the claim, in order to determine if the claim is progressively construed throughout the process until its final determination in the State's representative accusation.

Keywords: customs Law - Customs offenses - Customs Process - Uruguayan Customs Code.

\section{INTRODUCCIÓN}

En Uruguay, la sustanciación y resolución en vía judicial de los ilícitos aduaneros es de larga data. González (1946) ubica sus antecedentes en los albores de la vida independiente de nuestro país, y establece como un hito en nuestra legislación nacional la Ley de 12 de agosto de 1829 si bien resalta que es con la Constitución de 1830 que se consagra el régimen de judicialidad (pp. 362-366), y son diversas las leyes posteriores que determinan la jurisdicción del Poder Judicial en la materia, así como las que distribuyen su competencia ${ }^{[1]}$.

No obstante, la función jurisdiccional en materia infraccional aduanera ha estado dividida entre el Poder Judicial y la Aduana.

Como antecedente inmediato podemos citar a la Ley N. ${ }^{\circ} 13.318$, de 28 de Diciembre de 1964, en la redacción dada por el artículo 156 de la Ley N..$^{\circ} 16.320$, de $1^{\circ}$ de Noviembre de 1999, que dividía la jurisdicción y competencia exclusivamente para la sustanciación y juzgamiento de las cuestiones referidas a dos infracciones particulares: la infracción de contrabando y los asuntos relativos a los abandonos infraccionales. Así, en los asuntos que refirieran a supuestas infracciones de contrabando y en los abandonos infraccionales, sí éstos fueran de menor cuantía (asuntos que no excedieran a $350 \mathrm{UR}^{[2][3]}$ ), la Dirección $\mathrm{Na}$ cional de Aduanas ${ }^{[4]}$, sustanciaba el procedimiento y lo resolvía en primera instancia, con la eventual posibilidad de que su resolución fuera apelada ante al Poder Judicial (Esto es, ante los Juzgados Letrados de Aduana - con competencia territorial en los Departamentos de Montevideo y Canelones-, y los Juzgados

[1] En doctrina aduanera uruguaya se ha realizado una amplia y detallada revisión de los antecedentes de la función jurisdiccional y del procedimiento en materia de infraccional aduanero (González, 1946, pp. 362 a 409; Llorens Fernández, 1973).

[2] El artículo 156 de la Ley N. 16.320, de 1o de Noviembre de 1999, fijó el límite en Unidades Reajustables, sustituyendo el monto de $\$ 500.000$, fijado anteriormente por el artículo 494 , de la Ley $\mathrm{N} .{ }^{\circ} 14.106$, de 14 de Marzo de 1973, que sustituía el monto original de \$ 2.000 para la infracción de contrabando.

[3] La Unidad Reajustable es una unidad de medida, su valor es ajustado periódicamente en función del Índice Medio de Salarios cuantificándose las variaciones en los doce meses anteriores.

Recuperado de: http://www.ine.gub.uy/unidad-reajustable

[4] El inciso 2 o del artículo 2 del Decreto N. ${ }^{\circ}$ 133/93, de 16 de Marzo de 1993, comete a la Dirección Nacional de Aduanas la organización de sus reparticiones y dependencias, a fin de atender adecuadamente la competencia atribuida por los artículos 257 de la Ley N. ${ }^{\circ} 13.318$, en la redacción dada por el artículo 156 y concordantes de la Ley N. ${ }^{\circ} 16.320$, de 1 으 de noviembre de 1992. Por Órdenes del Día N. ${ }^{\circ} 62 / 93,63 / 93,64 / 93$ y 75/93, la Dirección Nacional da cumplimiento a lo dispuesto por el Poder Ejecutivo, y distribuye la referida competencia a nivel territorial. 
Letrados con competencia aduanera en el resto del país).

Por otra parte, los mismos asuntos (infracción aduanera de contrabando y abandonos infraccionales), cuando excedieran el referido límite, así como en el caso de las demás infracciones aduaneras, se sustanciaban y resolvían ante el Poder Judicial ${ }^{[5]}$, con la posibilidad de apelación en segunda instancia, y casación ante la Suprema Corte de Justicia ( Ley N. ${ }^{\circ}$ 13.318, 1964, art. 257).

No obstante esta jurisdicción compartida entre la Dirección Nacional de Aduana y el Poder Judicial, ciertamente, la realidad determinaba que el mayor número de asuntos fueran tramitados ante la Dirección Nacional de Aduanas, y ello, debido a que el límite cuantitativo de su competencia hacía que la mayoría de los supuestos de contrabando (infracciona más comúnmente procesable), recayeran ante la misma.
Con la aprobación del Código Aduanero de la República Oriental del Uruguay (2014) -en adelante, CAROU_ (aprobado por la Ley N. ${ }^{\circ}$ 19.276, de 19 de Septiembre de 2014) ${ }^{[6]}$ las infracciones aduaneras (a excepción de las infracciones de Contravención, que comprende hipótesis de trasgresiones procedimentales [Art. 200]) - pasaron a ser sustanciadas y resueltas ante el Poder Judicial. (Art. 227) ${ }^{[7]}$

Ello determinó que todos los asuntos que se estuvieran tramitando ante la Dirección Nacional de Aduanas, pasaran a continuar su sustanciación en vía judicial (Código Aduanero de la República Oriental del Uruguay, 2014, art. 269), y asimismo, que las denuncias que se hicieran a partir de la vigencia del CAROU fueran conocidas por los Juzgados competentes según el mismo Código. Ello tuvo como resultado que la entrada en vigencia de los aspectos procesales del CAROU fuera suspendido en dos ocasiones ${ }^{[8]}$.

[5] Siendo competentes los Juzgados Letrados de Aduana — con competencia territorial en los Departamentos de Montevideo y Canelones-, y los Juzgados Letrados con competencia aduanera en el resto del país dentro de los límites de sus jurisdicciones.

[6] Recuperado de: https://www.impo.com.uy/bases/codigo-aduanero/19276-2014

[7] E Artículo 227, enuncia lo siguiente:

Competencia según materia.-

1. El conocimiento de los asuntos relativos a infracciones aduaneras, excepto la infracción de contravención y lo dispuesto en el artículo 232 de este Código, corresponderá a los Juzgados Letrados de Primera Instancia del interior con competencia en materia aduanera y a los Juzgados Letrados de Aduana en los departamentos de Canelones y de Montevideo.

2. Conocerán los Tribunales de Apelaciones en lo Civil en segunda instancia y la Suprema Corte de Justicia en el recurso de casación, en caso de corresponder.»

Por su parte, el art. 232, dispone:

Los asuntos jurisdiccionales cuya cuantía no exceda la suma de $40.000 \mathrm{UI}$ (cuarenta mil unidades indexadas) se sustanciarán en instancia única ante los Juzgados de Paz Departamentales competentes en el interior de la República y el Juzgado Letrado de Aduana en los departamentos de Canelones y de Montevideo.

[8] La Ley 19.322, de 29 de Mayo de 2015, suspende la vigencia del artículo 275 de la Ley N. ${ }^{\circ} 19.276$, de 19 de setiembre de 2014, en lo que refiere a la derogación de los artículos 250, 257 a 261, 268 a 279, 283, 295 y 296 de la Ley N. ${ }^{\circ} 13.318$, de 28 de diciembre de 1964 y sus normas modificativas, en cuanto refieran a aspectos procesales, hasta el $1^{\circ}$ de marzo de 2016. Asimismo, la Ley N. ${ }^{\circ} 19.394$, de 20 de mayo de 2016, reitera el contenido de la Ley $\mathrm{N} .{ }^{\circ} 19.322$, suspendiendo la vigencia de los artículos mencionados de la Ley $\mathrm{N} .{ }^{\circ} 19.276$, en cuanto refieran a aspectos procesales, hasta el 16 de julio de 2017 . Como se puede observar, existió un período ventana en el que estuvieron vigentes las normas procesales editadas en el CAROU. 
Finalmente, el 17 de Julio de 2017, con la puesta en vigencia de las normas procesales contenidas en el CAROU, comenzaron a ser remitidos la totalidad de expedientes que hasta esa fecha llevaba la Dirección Nacional de Aduanas referentes a infracciones aduaneras de contrabando y abandono infraccional ( Ley N. ${ }^{\circ}$ 13.318, 1964, art. 257). En dicho período se remitió al Poder Judicial por parte de las distintas Administraciones de Aduana ${ }^{[9]}$ de la Dirección Nacional de Aduanas, un total de 8765 expedientes, de los cuales resultaron 2811 expedientes sin resolución (en trámite), y 5954 expedientes con resolución (en trámite) ${ }^{[10]}$.

Ahora bien, como lo señala la Exposición de Motivos que fue enviada al Parlamento acompañando el Proyecto de Ley de Código Aduanero de la República Oriental del Uruguay, fue de interés que el CAROU fuera un verdadero Código que sistematizara en mayor medida el Derecho Aduanero nacional. No obstante ello, no fueron suficientemente desarrollados los aspectos dogmáticos propios del Derecho Aduanero Sancionatorio, limitándose a un compendio de las infracciones aduaneras existentes, de fuentes legales diversas, y a la adopción del «régimen de responsabilidad subjetivo», que sin dudas constituyó un avance necesario, pero no suficiente en la materia.

Asimismo, en el CAROU se incluyeron las normas procesales referidas a la tramitación del contencioso aduanero. Dichas disposiciones desarrollan el Proceso Infraccional Aduanero de un modo sistemático, coherente y consistente, con las reformas establecidas, procurando corregir aquellas cuestiones que se revelaban en un proceso lento y costoso.

Pese a ello, y a la rica tradición judicial, algunas cuestiones procesales no fueron sopesadas con mayor rigor técnico, seguramente influidas por la concepción tradicional de asimilar el proceso contencioso aduanero con el proceso civil - fuera de su estructura-, descuidando algunos aspectos que, desde lo sustancial y por su carácter eminentemente sancionatorio, invaden la forma en que algunas de las cuestiones centrales del proceso se ven influidas.

Junto a ello, los cambios que se han suscitado en las cuestiones referidas a la función de la Aduana y de «lo aduanero», que sí se vio reflejada en la primera parte del CAROU, mediante un aggiornamento de las facultades de control de la Aduana, así como en otras cuestiones operativas y en los regímenes aduaneros, debió derivar en comenzar a centrarse en los aspectos «aduaneros» en lo que refiere a los ilícitos aduaneros, puesto que ellos pueden comprender supuestos que van más allá de lo tributario aduanero, y que se proyectan en el control aduanero, como materia pasible de especial tutela.

En razón de ello, pretendemos seguidamente insinuar algunos trazos que puedan servir para comenzar a recorrer algunas de las cuestiones que requieren ser profundizadas en materia de Derecho Aduanero Sancionatorio, y particularmente, algunas que refieren al Proceso de Conocimiento por Infracciones Aduanera en Uruguay.

\section{EL PROCESO INFRACCIONAL ADUANERO EN URUGUAY}

\subsection{Derecho Aduanero e infracciones aduaneras}

Puede definirse al Derecho Aduanero como el conjunto de normas de Derecho Público que regulan el ingreso, permanencia y egreso de mercaderías en relación a un territorio aduanero, y por tanto, los destinos

[9] Cada Administración de Aduana era competente en una circunscripción territorial determinada.

[10] Recuperado de:

http://poderjudicial.gub.uy/images/2017/circulares_2017/155-2017.pdf 
y los regímenes aduaneros en los cuales se puede incluir una mercadería que se importa o exporta, así como los sujetos que intervienen en aquellos; regulando los diversos requisitos sustanciales, tributarios y procedimentales, las restricciones y prohibiciones, y los ilícitos aduaneros. En similar sentido se ha expresado Basaldúa. (1997, p. 4)

Ese conjunto de normas que regulan el ingreso, permanencia y egreso de las mercaderías en relación a un territorio aduanero, establecen reglas de conducta, que determinan un hacer o un abstenerse de hacer algo.

Como es sabido, toda norma puede ser acatada y cumplida por los sujetos obligados por la misma, pero también puede ser incumplida.

Ahora bien, sin perjuicio que una determinada norma ordene realizar o abstenerse de realizar una conducta determinada, su incumplimiento (por acción u omisión) no tiene como consecuencia per se la aplicación de una sanción. Esto es, no todo incumplimiento de un precepto normativo tiene como resultado la imposición de una sanción.

Para que el incumplimiento de un determinado precepto tenga como consecuencia la aplicación de una sanción, se deben cumplir tres requisitos, a saber: a) que determinada conducta (activa u omisiva) haya sido previamente seleccionada por una norma de rango legal (en aplicación del principio de legalidad) como de entidad suficiente para que quien la realice sea pasible de una determinada sanción, salvo que dicha norma (u otra norma legal) le atribuya a otro sujeto las consecuencias jurídicas del actuar del primero (junto a aquel o en lugar de aquel [CAROU, 2014, art. 219]); b) que un sujeto actúe (realice) dicha conducta (activa u omisiva; y c) que mediante un procedimiento administrativo o un proceso judicial, previamente establecido a tales efectos, se constate la existencia de dicha actuación, así como una serie de elementos requeridos a dicho actuar, para que le sea atribuido al sujeto que haya sido autor de tal acción u omisión, o al responsable por el actuar de aquel (junto a aquel o en lugar de aquel), las consecuencias jurídicas previstas en aquella norma. (Varela, 2017, pp. 238-239)

Así, en lo que refiere a las sanciones, siguiendo a Falcón y Tella y Falcón y Tella (2005), puede decirse que estás son previsiones normativas que se producen frente a una conducta disvaliosa, cuando falla la finalidad primaria del Derecho, que es la obligatoriedad (p. 91). Dicen los autores, que el objetivo primario del Derecho es que se cumpla lo ordenado por él -acción- o que se omitan las acciones contrarias a lo prohibido por él —omisión-. Así, la eficacia primaria del Derecho son las conductas. Las normas primarias son normas de conducta, que consisten en mandatos - positivos - , prohibiciones - negativas - o permisiones — conductas neutras-. No obstante, cuando las normas primarias —de conducta, destinadas a la colectividad - no son observadas, es cuando surgen las normas secundarias-sancionadoras, destinadas a ser aplicada por los jueces o tribunales. (Falcón y Tella y Falcón y Tella, 2005, p. 91)

La sanción o castigo deriva del carácter obligatorio del Derecho. La cual se expresa por el doble carácter imperativo y coactivo. La «imperatividad» se refiere al plano de la previsión normativa, a nivel legislativo, de la sanción en potencia, en cambio la «coactividad» alude a la realización del acto de dicha sanción. (Falcón y Tella y Falcón y Tella, 2005, p. 91)

Así, en el plano de la «imperatividad» la sanción juega un papel porque intimida a la generalidad de la población — prevención general-, en cambio, en el nivel de la «coactividad» la sanción actúa respecto del individuo concreto que ha infringido la norma penal y a quien se aplica en consecuencia el castigo —retribución-. (Falcón y Tella y Falcón y Tella, 2005, pp. 88-89)

Las infracciones son, en esencia, descripciones de conductas antijurídicas, recogidas en normas legales, cuyo cumplimiento por 
un sujeto - que actúa la conducta descripta, haciendo u omitiendo hacer la misma - tiene como resultado la imposición de una sanción, toda vez que dicha actuación puede serle atribuida en algún grado de subjetividad (culpa o dolo), salvo que la ley determine que la imputación de responsabilidad fuera objetiva (Varela, 2017, pp. 238 y 239). Asimismo, la imposición de la sanción puede recaer en el sujeto que actúa la conducta descripta o en otro sujeto (en lugar de aquel o junto a aquel).

Por su parte, son infracciones aduaneras aquellas descripciones de conductas antijurídicas, activas u omisiva, recogidas en normas legales que, simultáneamente, pretenden evitar determinadas transgresiones a la legislación aduanera, mediante la previsión normativa de retribuir la ejecución de la conducta con una sanción, y con carácter coactiva, para los casos que efectivamente se actúe por un sujeto la conducta descrita, tendrán por resultado la imposición de la sanción prevista, respecto del sujeto que se determine como responsable de aquella conducta, que puede ser el autor de aquella u otro sujeto, en lugar de aquel o junto a aquel.

Cabe observar que en la legislación aduanera de Uruguay, con fuente en el CAROU, no se encuentra una definición o concepto de «infracción aduanera», dentro del artículo 2 del mismo, el cual contiene las denominadas «Definiciones básicas». Ello demuestra las fuentes diversas del Código, y las carencias metodológicas al momento de sistematizar la normativa de las referidas fuentes, por cuanto existe un corte claro entre la parte del Código que procede sustancialmente del Código Aduanero del Mercosur, y la parte que contempla diversas disposiciones nacionales que se conglobaron en el Código, con fuente principalmente en la Ley $\mathrm{N} .{ }^{\circ} 13.318$.
No obstante ello, tampoco resulta una definición de «infracciones aduaneras» dentro del Título XIII del CAROU, que regula el «Régimen Infraccional», ni en el Capítulo I de «Infracciones Aduaneras», prefiriéndose la simple nominación de las diversas infracciones en el artículo 199, primero del Capítulo I, del Título XIII. ${ }^{111]}$ Siguiéndose de esta forma a las normas antecedentes ${ }^{[12]}$.

En el Código Aduanero Argentino, en cambio, se establece un concepto de infracciones aduaneras, al decirse que son infracciones aduaneras los hechos, actos u omisiones que se reprimen por transgredir las disposiciones de la legislación aduanera respectiva. (Cotter, 2014, p. 1147)

Como se refirió previamente, lo que se pretende con las sanciones aduaneras es, en primer término, evitar determinadas transgresiones a la legislación aduanera, y en caso de no lograrse aquello, en segundo término, reprimir dichas conductas.

Como se dijo, no todas las conductas que pueden ser contrarias a una norma - por tanto, antijurídicas - serán infracciones aduaneras, puesto que algunas transgresiones, por su poca trascendencia o lesividad pueden no tener relevancia para ser contempladas como conductas punibles por el legislador, por no afectar de manera relevante el bien jurídico que se pretende tutelar por el elenco de infracciones. En igual sentido, algunas otras conductas, aun siendo antijurídicas, trascendentes y lesivas, pueden no haber sido previstas por el legislador, y por tanto, ser atípicas, y con ello, no serán alcanzadas por una sanción.

Ahora bien, compartimos con Mazz (2001), Profesora uruguaya de Derecho Financiero,

[11] En su art. 199, relativo a Infracciones Aduaneras, el Código Aduanero de la República Oriental del Uruguay, 2014, dispone:

Son infracciones aduaneras: la contravención, la diferencia, la defraudación, la defraudación de valor, el abandono infraccional, el desvío de exoneraciones y el contrabando.

[12] Ver: Ley N. ${ }^{\circ} 6.839,1918$, art. 1; Decreto-Ley N. ${ }^{\circ}$ 10.257, 1943, art. 1; y Ley N. ${ }^{\circ}$ 13.318, 1964, art. 245. 
que el concepto de «infracciones aduaneras» es muy amplio, en el sentido de las conductas que atrapa y sanciona (p. 261). Y lo es, más que el que comúnmente se le reconoce, puesto que no solo se deben relacionar con la infracción a las normas tributarias aduaneras, sino con la violación de cualquier norma de Derecho Aduanero, tanto aquellas que configuran obligaciones tributarias aduaneras, como las que regulan los procedimiento, el control (Mazz, 2001, p. 261). Y extendemos nosotros, las que regulan los regímenes de prohibiciones ${ }^{[13]}$.

De tal forma, como es señalado por el CAROU (2014), la trasgresión de la legislación aduanera puede estar dada, por ejemplo, por la omisión en el cumplimiento formal de las normas que regulan el procedimiento aduanero, sin importar que la misma provoque pérdida de renta fiscal o no (art. 200); la diferencia que pueda resultar en la clasificación arancelaria de una mercadería realizada por un declarante en relación a la que hubiera correspondido, toda vez que provoque pérdida de renta fiscal (art. 201); la declaración aduanera que distorsione el valor en aduana de una mercadería en perjuicio de la renta fiscal (art. 205); la introducción de una mercadería a territorio aduanero sin cumplir con los trámites requeridos para su ingreso, provocando con ello la pérdida de renta fiscal (art. 209); o el ingreso de mercadería a territorio aduanero, mediante un despacho regula y previo pago de tributos, pero sin cumplir los requisitos esenciales para la importación definitiva de la referida mercadería. (art. 209)

Cada uno de estos supuestos resulta recogido en un tipo infraccional, que determina una consecuencia punitiva para quien actúa (por acción u omisión) dichas conductas ${ }^{[14]}$.
Queda claro que el concepto que debe tenerse de «infracción aduanera» tendrá relación directa con los supuestos que resulten del derecho positivo del país a que se refiera. No obstante, debemos advertir que las transgresiones que se reprimen en el caso del infraccional aduanero, no solamente deberían referir a la simple falta de percepción de tributos debidos como consecuencia de la realización de hecho generador, sino que, las transgresiones deberían referir también a diversas disposiciones no tributarias, como las que refieren al control aduanero, o las que pueden contemplar prohibiciones de importar o exportar.

\subsection{Contenido, necesidad y finalidad del Pro- ceso Infraccional Aduanero}

Ha señalado Del Cueto (1970), que todos los ilícitos aduaneros poseen sus correspondientes sanciones, y para la constatación de la infracción y la imposición de la sanción que corresponda, existe todo un sistema de normas que regulan la secuencia de actos de relevancia jurídica conducentes a la constatación y punición de la infracción, denominado contencioso aduanero. (p. 66)

En tal sentido, se ha afirmado en la doctrina procesalista uruguaya que el Proceso Aduanero es «constitutivo necesario», puesto que la satisfacción solo es posible obtenerla a través del proceso, y por tanto, requiere necesariamente del proceso para alcanzar su resultado, esto es, la imposición de la sanción. (Colombo y Torello, 1980, p. 55)

Creemos que actualmente, existen determinados supuestos - algunos reconocidos ya en tiempo de esa afirmación-[15] que determinan una conclusión diversa, puesto que el «Reconocimiento Administrativo y Acuerdo de

\footnotetext{
[13] Véase en igual sentido lo expresado en la Doctrina argentina (GARCÍA VIZCAINO, 2010, p. 407).

[14] Como se puede verificar de los artículos anteriormente referidos.

[15] Nos referimos en concreto a la hipótesis de la Ley N. ${ }^{\circ}$ 13.318, 1964, artículo 250, Lit. A.
} 
pago» (CAROU, 2014, artículo 217), la «Auto revisión» (CAROU, 2014, artículo 221) y el «reconocimiento» en el «Procedimiento de diferencia o defraudación de valor previo al libramiento» (CAROU, 2014, artículo 224) —que son todos procedimientos administrativos, y no procesos judiciales - habilitan, previo el necesario reconocimiento del declarante, el pago de los tributos correspondientes, y también -y en ello nos basamos_ la imposición de las sanciones.

Por tanto, puede decirse que, salvo los supuestos referidos precedentemente (recogidos en el artículo 217, 221 y 224 del CAROU), solamente se puede alcanzar el resultado previsto en el ordenamiento Aduanero Sancionatorio, por medio del «Proceso de Conocimiento por Infracciones Aduaneras», incluso en los supuestos del 248 del CAROU ${ }^{[16]}$.

Pero aún ello, solamente se puede alcanzar la determinación de si la conducta es reprochable, y en caso de así serlo, la imposición de la consecuente sanción establecida por el ordenamiento aduanero, si se recorre el camino establecido legalmente a tal fin. Lo que supone el cumplimiento estricto de las disposiciones que regulan el Proceso Aduanero ante la autoridad jurisdiccional competente, hoy exclusivamente el Poder Judicial[17].

Todo ello teniendo en consideración, como lo ha expresado el Profesor argentino Horacio Alais, que:

Las normas procesales no se han de reducir a una mera técnica de organización formal de los procesos, sino que, en su ámbito específico, tienen como finalidad y objetivo ordenar adecuadamente el ejercicio de los derechos en aras de lograr la concreción del valor justicia en cada caso y salvaguardar la garantía de la defensa en juicio. (Alais, 2008, p. 277)

Por otra parte, Colombo y Torello (1980) han expresado en relación a los procesos jurisdiccionales aduaneros en Uruguay, que estos son los que se promueven frente a hechos que tienen la apariencia de una infracción aduanera, cuando se descubre, denuncia o se tiene noticia de una de esas infracciones o de algún hecho constitutivo de las mismas. Entendemos, en tal caso, que es objeto de la denuncia la «eventual» infracción aduanera $-\mathrm{y}$ ello en condicional-, pues, como bien advierten los mencionados procesalistas, «en el proceso aduanero se indaga si, en verdad, se ha cometido una infracción fiscal; quien o quienes participaron en ella; que responsabilidad les incumbe y la sanción que se les debe imponer». (Colombo y Torello, 1980, p. 9)

Ello ha llevado a decir a los referidos autores, que:

La finalidad de este proceso es la de reprimir las infracciones del régimen legal y reglamentario que regula lo concerniente a la introducción, extracción o tránsito de mercaderías o efectos, pues en nuestro derecho tales operaciones siempre están sujetas a un régimen de requisitos y, por lo general, al pago de ciertos gravámenes; requisitos o gravámenes que son los que se eluden o pretenden eludir por medio del intento o la consumación del acto infraccional. (Colombo y Torello, 1980, p. 9)

[16] Código Aduanero de la República Oriental del Uruguay, 2014, art. 248, el que dispone:

Confesión.- Cuando el imputado confiese la infracción cometida o reconozca los hechos constitutivos de la misma, se pasará a plenario, sin necesidad de otra prueba ni trámite, y se dictará la sentencia respectiva, previo traslado al representante fiscal por el término improrrogable de nueve días hábiles.

[17] Salvo en lo que refiere a la Infracción Aduanera de Contravención que es procesable ante la Dirección Nacional de Aduanas (Código Aduanero de la República Oriental del Uruguay, 2014, art. 226), y los supuestos recogidos en el Código Aduanero de la República Oriental del Uruguay, 2014, arts. 217, 221 y 224, que tramitan administrativamente frente a la Dirección Nacional de Aduanas. 
Nos permitimos disentir con tal afirmación, o por lo menos matizar la misma, puesto que, a nuestro juicio, no se puede sostener que la finalidad del proceso aduanero sea reprimir las infracciones aduaneras, sino que, la finalidad del mismo debe enmarcarse en el juzgamiento de la conducta denunciada, atribuida a uno o más personas (físicas o jurídicas), para determinar si la misma puede ser encajada en el tipo infraccional previsto, y solo en tal caso, imponer las consecuencias previstas por la norma legal.

Por tanto, en primer término, el Proceso Aduanero debe estar dirigido a procurar la constatación judicial de la ocurrencia y veracidad de los hechos denunciados, y su atribución a una o más personas. En segundo término, debe estar orientado a constatar la encajabilidad (o no) de los hechos en la norma infraccional, y solo en caso de verificarse ello, se debe juzgar la conducta del autor (o autores) mediante la apreciación de la culpabilidad del sujeto (salvo que la responsabilidad le fuera imputada a título de responsabilidad objetiva). Finalmente, en tercer término, salvo causa de justificación existente ${ }^{[18]}$, debe imponerse a su autor o autores y/o a los demás responsables, las consecuencias previstas en la norma legal, siempre dentro de sus límites, con el grado de proporcionalidad a la conducta desarrollada por el autor o autores, garantizando al infractor, en todos los casos, el ejercicio pleno de sus derechos de defensa.

Debe recordarse lo referido por el Profesor Tarigo (1994), en relación a la finalidad del proceso, decía: «La finalidad del proceso es aquella que le asigna el Derecho objetivo y no la que persigan subjetivamente los sujetos que en él actúan». (p. 21)
Así entonces, la finalidad del Proceso Aduanero (Rectius: «Proceso de Conocimiento por Infracciones Aduaneras») es determinar si los hechos que son denunciados por lo funcionarios aduaneros, o cualquier otro funcionario del Estado, o por un particular, y puestos en conocimiento de la autoridad judicial, han sucedido, y en tal caso, si constituyen o no una infracción aduanera; y de serlo, determinar quién o quiénes son los autores de la misma, juzgar su o sus conductas, e imponer a su o sus responsables las sanciones establecidas legalmente como reproche a dicha conducta - multa, comisos, costas y costos del proceso, según corresponda a la infracción de que se trate -; así como, en los casos que proce$\mathrm{da}^{[19]}$, disponer el pago de los «tributos correspondientes», y ello, toda vez que así haya sido previamente requerido por el Representante Fiscal, único titular de la acción en el contencioso aduanero (Varela, 2017, p. 253).

\subsection{El proceso aduanero es "aduanero»}

La doctrina procesalista uruguaya ha remarcado que el proceso contencioso aduanero es un proceso civil (Colombo y Torello, 1980; Torello et al., 1985 y Marabotto y Abal, 1988).

En esta línea, es del caso remarcar que Colombo y Torello (1980), partiendo de la categorización contenida en las normas positivas de la época de su obra, especialmente con fuente en el Código de Procedimiento Civil, y en el Código de Organización de Tribunales Civiles y de Hacienda, entienden que, en razón de la materia de su objeto, los procesos se clasifican en civiles o criminales, según sea

[18] Por ejemplo, estado de necesidad, el cual excluye la ilicitud.

[19] En tal sentido, debe recordarse que no todas las infracciones suponen la determinación de un responsable, y el pago de los tributos correspondientes, como es el caso del abandono infraccional (Código Aduanero de la República Oriental del Uruguay, 2014, art. 207). Asimismo, en los casos de contrabando cuando se verifica «la violación de requisitos esenciales para la importación o exportación definitiva de determinadas mercaderías que establezcan leyes y reglamentos especiales aún no aduaneros», normalmente ello no supone el no pago de los tributos. 
el interés o la pena (CPC, 1978, artículo $2^{[20]}$ ), y por ello, los procesos jurisdiccionales aduaneros se deben clasificar como procesos civiles (Colombo y Torello, 1980, p. 55). Agregando además los referidos autores, que pese a que su estructura guarde gran analogía a la de los procesos penales - como se verá infra-, y en los mismos se persiga la imposición de una sanción, el artículo 2 del Código de Organización de los Tribunales (1993) ${ }^{[21]}$ resuelve la cuestión al determinar que sólo se consideran penas penales aquellas aplicadas por los jueces que tienen jurisdicción y competencia en materia penal (Colombo y Torello, 1980, p. 55). En igual sentido se expresaron Marabotto y Abal (1988, p. 300). Asimismo éste criterio es incluso compartido recientemente por Pablo Labandera. (2016, p. 563)

No obstante, el Maestro Couture advertía, con anterioridad, que:

El concepto simplista del art. 2, C.P.C., que divide el juicio en civil o criminal según tenga por objeto el interés o la pena, fue virtualmente sustituido por la abigarrada noción del art. 2, C.O.T., según el cual es materia civil la que no tiene por objeto la imposición de la pena. Pero ambas definiciones son insuficientes no bien se tenga en cuenta que en el proceso penal también está en juego un interés y en el proceso civil también se imponen penas. (Couture, 1964, p. 82)
Por nuestra parte, entendemos que, ciertamente, la clasificación tradicional en la materia (Colombo y Torello, 1980; Torello et al., 1985 y Marabotto y Abal, 1988), que parte de la distinción binaria de procesos civiles y penales, y que considera al Proceso Aduanero como Civil, es insuficiente a efectos de determinar la real dimensión del mismo, o al menos, para ubicar correctamente al Proceso de Conocimiento por Infracciones Aduaneras del CAROU (como también lo era para ubicar al Contencioso Aduanero regulado por la Ley $\mathrm{N}^{\circ}{ }^{\circ}$ 13.318).

En tal sentido, debe advertirse que en el Proceso de Conocimiento por Infracciones Aduaneras puede resultar la imposición de una sanción, y ello influye de sobremanera en la trascendencia que tiene, entre otras cosas, la distribución de la carga de la prueba entre las partes en el proceso, la incidencia de la presunción de inocencia que impregna todo el Derecho Sancionatorio, así como el valor de los indicios, o el estándar de la prueba en la valoración de la misma por el juez; o las pautas de apreciación de la culpa a los fines de imposición de la sanción; o los efectos del fallecimiento del infractor en el proceso cuando el mismo está en curso. Asimismo, y como referiremos posteriormente, el objeto del proceso aduanero se conforma de modo distinto al del proceso civil.

Por ello, entendemos que el Proceso Aduanero ha alcanzado su peculiaridad frente

[20] El Código de Procedimiento Civil, 1978, en su art. 2, disponía:

El juicio es civil ó criminal, según tenga por objeto el interés ó la pena. Recuperado de: https://www.impo. com.uy/armandugon/11/8?carfin $=194$

[21] El Código de Organización de los Tribunales Civiles y de Hacienda, 1933, en su art. 2, disponía:

La facultad de conocer de las causas civiles, de hacienda y contencioso-administrativas, y de hacer ejecutar lo juzgado en la forma que en cada caso corresponda, pertenece exclusivamente a los Tribunales que establece la ley.

Por Tribunales entiende esta ley, tanto los colegiados como los unipersonales; y por causas civiles, de hacienda y contencioso-administrativas, según su naturaleza, aquellas que no tienen por objeto la imposición de una pena, reputándose que no son penas, a este efecto, las sanciones pecuniarias de cualquier entidad cuando su imposición no esté cometida a los jueces del orden penal y subordinada a la instrucción de proceso en legal forma, ni obste a la instrucción simultanea o ulterior de tales procesos para el castigo por vía criminal del propio hecho sancionable.

Recuperado de: https://www.impo.com.uy/bases/leyes/9164-1933 
al proceso civil, que determinan su autonomía procesal, al inspirarse en principios diversos a aquellos, en tanto que en ellos surge la potencialidad del ejercicio punitivo del Estado, debiéndose categorizar dentro de los Procesos Sancionatorios, encontrándose junto al Proceso Penal, del cual claramente se distingue, por su naturaleza y contenido.

\subsection{La materia del Proceso Aduanero es la «materia aduanera»}

Se ha señalado que la materia específica de los procesos aduaneros es la hacienda, en atención a dos circunstancias: la primera, por razón de las normas sustantivas que se aplican, y la segunda, por su específica finalidad, que es la de cobrar tributos impagos y aplicar sanciones de naturaleza tributaria (Colombo y Torello, 1980, p. 55). En similar sentido, han expresado Marabotto y Abal (1988), que en el proceso aduanero -al menos en su forma contenciosa - lo que se quiere determinar es si, en verdad, se ha cometido una infracción fiscal, en tanto afecta los intereses del Fisco, es decir, del Estado, enfocado como el Erario Público o la Hacienda Pública, quién es su autor, qué responsabilidad le cabe y por ende, finalmente, cuál es la sanción que corresponde imponerle. (p. 291)

No obstante, ésta visión no es acorde al actual grado de desarrollo del Derecho Aduanero.
Creemos, en cambio, que por su la naturaleza, la materia del Proceso Aduanero es sin dudas aduanera, puesto que éstas normas son las que se transgreden, y que la finalidad de las sanciones por infracciones aduaneras no se limita al cobro de tributos impagos y a la aplicación de sanciones de naturaleza tributaria, puesto que en algunos casos, aún sin la existencia de pérdida o peligro de pérdida de renta fiscal - que si bien es requerida en la mayoría de las infracciones en nuestro actual ordenamiento ${ }^{[22]}$ — se puede configurar una infracción aduanera, como es la hipótesis de la Infracción Aduanera de Contrabando, cuando, sin pérdida de renta fiscal, se verifica «la violación de requisitos esenciales para la importación o exportación definitiva de determinadas mercaderías que establezcan leyes y reglamentos especiales aún no aduaneros», elemento éste que no es hacendístico (CAROU, 2014, art. 209; Ley N. ${ }^{\circ} 13.318,1964$, art. 253).

Podemos afirmar que en el régimen infraccional con fuente en el CAROU, la mayoría de las hipótesis infraccionales requieren como elemento central la «pérdida de renta fiscal», y por ello, pese los alegados esfuerzos por su depuración y mejora, el trabajo emprendido para aprobar un nuevo Código Aduanero no supuso una verdadera revisión dogmática de sus contenidos, limitándose a reagrupar en un único texto normativo el elenco de las infracciones aduaneras existentes ${ }^{[23]}$.

[22] A la que se ha ampliado el perjuicio al Fisco en la «concesión de incentivos o beneficios económicos o tributarios».

[23] Así, en la Exposición de motivos que acompañó el Proyecto de Código Aduanero de la República Oriental del Uruguay se dijo:

Infracciones aduaneras (artículos 198 a 216). Actualmente, las infracciones aduaneras se encuentran reguladas en distintas normas, aprobadas en diferentes momentos a lo largo de varias décadas y en función de diferentes concepciones y problemáticas. Esto no solo implica un desfase respecto de la realidad actual de los incumplimientos de la legislación aduanera sino que también impide una interpretación armónica del conjunto de infracciones. Es más, existen dudas de si algunas de ellas siguen estando vigentes. EI CAROU incorpora un todo orgánico, que considera a todas las infracciones aduaneras bajo los mismos principios y procedimientos, otorgando certeza jurídica y reglas claras tanto a quienes se impone la norma como a quienes la deben aplicar. 
No obstante, el cambio que se desarrolla en las nuevas funciones de la Administración Aduanera y de «lo aduanero», derivará en una profundización de la relevancia del «control aduanero» como bien jurídico tutelado inmediato, debiéndose redimensionar la importancia actual de «la pérdida de renta fiscal».

Asimismo, otros bienes jurídicos mediatos (como la salud pública, el medio ambiente, la producción nacional, entre tantos otros) dimensionan de forma significativa la finalidad de las normas aduaneras, donde los bienes objetos de protección son a su vez supraindividuales, todo lo cual derivaran en el desarrollo más profundo de la dogmática aduanera, con base en principios propios, que hoy en nuestro Derecho Aduanero nacional aún se encuentran en etapa germinal.

Como ha referido Radovic (2010), la esencia de la norma punitiva es la protección de un bien jurídico; la gravedad de la infracción y la drasticidad de la sanción, forzosamente tienen que estar en proporción con la categoría del bien jurídico que la ley protege y con la intensidad de la lesión de la conducta antijurídica ocasionada. (p. 78)

Por tanto, es trascendente la visión más profunda, en cuanto a que no sólo se debe incluir la faz tributaria en las referidas infracciones, dado que la naturaleza de Derecho Adua- nero incluye una diversidad de disposiciones normativas, que comprenden las normas de protección a la seguridad nacional, ecología y medio ambiente, las de salud pública, las fiscales, las proteccionistas de la producción nacional, las proteccionistas del interés financiero del Estado, entre tantas otras.

Entendemos que, a medida que se vaya avanzando en la dogmática aduanera, se comprenderá la necesidad de ampliar el elenco de supuestos que configuran las transgresiones a las normas aduaneras, principalmente, cuando se alcance a redefinir el bien jurídico, o los bienes jurídicos, que se deben proteger con cada una de las mismas, y en igual sentido, se depuren efectivamente algunas figuras típicas.

\subsection{Objeto del «Proceso de Conocimiento por Infracciones Aduaneras»}

EI CAROU distingue tres Procesos dentro del denominado «Proceso Infraccional Aduanero»[24], los cuales se encuentran previstos en el Capítulo IV del Título XIII (Régimen Infraccional), a saber: a) el «Proceso de Abandono Infraccional», previsto en la Sección II del referido Capítulo; b) el «Proceso de Conocimiento por Infracciones Aduaneras», previsto en la Sección II del precitado Capítulo[25]; y c) el «Proceso de Ejecución», previsto en la Sección IV, de aquel Capítulo[26].

En este sentido, al momento de elaborar el proyecto se consideraron todas las infracciones aduaneras vigentes, se contrastaron con el derecho comparado y se compendiaron en un solo cuerpo, reduciendo el elenco de las mismas y actualizando su redacción a efectos de facilitar su comprensión y aplicación. También se simplificaron las sanciones, cuando fue posible.

[24] Que como categoría en el Código Aduanero de la República Oriental del Uruguay debió denominarse en plural, esto es: «Procesos Infraccionales Aduaneros», dado que contempla dentro de dicha categoría tres especies, con regulaciones y objetos propios.

[25] Abarca los artículo 234 a 250 del Código Aduanero de la República Oriental del Uruguay..

[26] Sin perjuicio de ello, debe anotarse que el CAROU también refiere al «Juicio Ejecutivo Aduanero» en el artículo 191, artículo que remite al Capítulo Cuarto del Código Tributario, incluso en lo relativo a la adopción de medidas cautelares, y las normas aplicables del Código General del Proceso, el cual es un Proceso Judicial. Asimismo, el Código Aduanero de la República Oriental del Uruguay, 2014, art. 99, prevé el denominado «Proceso relativo al abandono no infraccional», que también tramita ante el Poder Judicial, ante los ante 
El «Proceso de Conocimiento por Infracciones Aduaneras» es el proceso principal por el que se sustancian las infracciones aduaneras que son procesables judicialmente.

Ahora bien, corresponde preguntarse: ¿cuál sería el objeto en un Proceso de Conocimiento por Infracciones Aduaneras?

Para Palacio (2001), en el proceso civil, el «objeto del proceso» es la materia alrededor de la cual gira su iniciación, desenvolvimiento y extinción. Así, dicho objeto se halla representado por una o más pretensiones o peticiones extra contenciosas, según se trate, respectivamente, de un proceso de conocimiento o de un proceso voluntario. (p. 92)

Con un carácter eminentemente civilista, Couture (1983) define a la «pretensión» como la autoatribución de un derecho por parte de alguien que, invocándolo, pide que se haga efectiva a su respecto la tutela jurídica. (p. 473)

Enseña Palacio (2001) que si bien la pretensión y la oposición (o defensa) aparecen así como anverso y reverso de una misma figura, solo la primera constituye «objeto» del proceso. Los distintos tipos de oposiciones que el demandado pueda formular solo tienen incidencia en la delimitación del área litigiosa y en la mayor amplitud que imprimen el tema decidendum, pero no alteran el objeto del proceso, que está exclusivamente fijado por el contenido de la pretensión. (p. 123)

Ahora bien, las particularidades de la estructura del proceso aduanero ${ }^{[27]}$, invertida en relación al proceso civil ordinario ${ }^{[28]}$, determina que, sobre la base de la existencia prima facie de elementos que hagan que la situación de hecho denunciada se verifique en el sentido indicado en la denuncia - mediante el ofrecimiento y diligenciamiento de la prueba-, la pretensión se pueda exteriorizar recién en la Demanda Acusación Fiscal, por parte del titular de la acción fiscal, al determinar la subsunción de la conducta del caso referida en el precepto infraccional, y con ello, consecuentemente, sea solicitada la imposición de la sanción prevista en la norma frente a tal hipótesis contra el responsable de la misma.

Así entonces, en la estructura procesal establecida por el CAROU (2014), luego de presentada una denuncia (arts. 236 a 238), y realizado las primeras instrucciones (arts. 231, 240 y 241), se fija una Audiencia Indagatoria en la que declara ante el Juez el denunciado, asistido por su Defensor y en presencia del Representante Fiscal (art. 242). En el caso de que exista mérito para presumir la configuración de una infracción, se podrá solicitar por el Representante Fiscal (art. 244), y se resolverá por el Juez si corresponde la iniciación del sumario (art. 245, num.2) contra el denunciado (art. 246). Desde este momento se abre una segunda etapa, de contenido probatorio, en la que se produce el ofrecimiento de pruebas (autos de manifiesto) por el sumariado y el Representante Fiscal (art. 247). Agotado el diligenciamiento de la prueba propuesta, se confiere el traslado al Representante Fiscal, para que, de entender que surge probado un hecho infraccional, ejerza su acción, mediante la Demanda Acusación Fiscal (art. 249), y de esta forma, estando ya en etapa plenamente adversarial, se dispone el traslado de la misma para que el acusado articule sus defensas (art. 250, num. 1). Finalmente, se dictara sentencia por el Juez de la causa. (art. 250, num. 2)

los Juzgados Letrados de Primera Instancia del interior con competencia en materia aduanera y ante los Juzgados Letrados de Aduana en los departamentos de Canelones y de Montevideo.

[27] Denuncia - Calificación - Sumario [diligenciamiento de prueba] - Plenario [Demanda Acusación - Contestación] - Sentencia.

[28] Demanda - Contestación - Fijación del objeto del proceso y de la prueba - Etapa probatoria [diligenciamiento de la prueba] - Alegatos - Sentencia 
En tal sentido, podemos afirmar que, en materia sancionatoria en general, e infraccional aduanera en particular, la pretensión consiste en la manifestación de voluntad, en ejercicio de un poder-deber, dirigido a un tercero, afirmando que se ha verificado un hecho tipificado como infracción en una ley, y por ello se reclama la imposición a un sujeto de las consecuencias previstas, sea como autor, coautor o cómplice de tal hecho, o respecto de sus responsables.

Conforme enseña Palacio (2001):

Ya se ha explicado que la acción no puede confundirse con la pretensión, pues aquélla no es otra cosa que el derecho en cuya virtud la pretensión puede ser llevada a la consideración de un órgano judicial. Sólo faltan entonces destacar que tampoco puede ser identificada con la demanda, en tanto ésta sólo no constituye el objeto del proceso sino que es sólo un medio de promoverlo o, en otras palabras, un mero acto de iniciación del proceso (p. 95).

Por ello, también podemos afirmar, que el Proceso de Conocimiento por Infracciones Aduaneras está delimitado por las únicas pretensiones posibles, las cuales giran en torno a la aplicación de un precepto infraccional aduanero, que está dado por una única hipótesis infraccional dentro del repertorio de infracciones previstas legalmente ${ }^{[29]}$.

Así, el Proceso de Conocimiento por Infracciones Aduaneras tiene por objeto la aplicación de las normas aduaneras, toda vez que se verifique el supuesto de hecho normativo de las infracciones aduaneras previstas en la Ley. Claro está, en el sustrato del referido proceso se encuentra la estructura lógica de las normas infraccionales aduaneras: dado un hecho $(A)$ considerado infraccional por la Ley, debe de aplicarse la correspondiente sanción (B), para lo cual, como se dijo, se requiere del Proceso de Conocimiento por Infracciones Aduaneras. En similar sentido se ha referido Greif (1997) en el Proceso Penal Uruguayo (p. 7).

No obstante ello, si la pretensión resulta verdaderamente exteriorizada en la etapa del Plenario - con la Demanda Acusación Fiscal-, cabe preguntarse si es recién en ese momento en que se puede conformar el objeto del Proceso Aduanero. En otro sentido, si la vinculación entre el objeto del proceso y la pretensión es tan estrecha como en los Procesos Civiles.

Entendemos que, a diferencia del Proceso Civil, el objeto del Proceso Aduanero se desarrolla y cristaliza de forma progresiva en las diversas etapas del mismo, hasta alanzar su fijación definitiva en la Demanda Acusación Fiscal.

Si se observa, el conjunto de hechos de la realidad que son sometidos al proceso judicial son aportados generalmente por terceros. Como se refirió, la finalidad del proceso es determinar si son de aplicación los preceptos infraccionales a los hechos denunciados, y en tal caso atribuir las consecuencias jurídicas previstas en el ordenamiento. No obstante, ellos son determinados de manera progresiva.

Así, los grados de certidumbre sobre la existencia de mérito para ir conformando la pretensión se desarrollan en el propio proceso, de manera progresiva, dado que los Procesos Aduaneros no se inicia con la pretensión como los Procesos civiles.

Si como creemos, se le asigna relevancia al objeto del proceso desgajándolo de la ligazón civilista de la pretensión, el objeto de proceso se podrá ir conformando a lo largo del mismo. Ello sería instrumentalmente apto para

[29] Actualmente consagradas en el Código Aduanero de la República Oriental del Uruguay, 2014, art. 201 (Diferencia), art. 204 (Defraudación), art. 205 (Defraudación de Valor), art. 208 (Desvío de exoneración), art. 209 (Contrabando), y art. 212 (Adquisición, recepción y posesión de mercaderías objeto de contrabando). 
determinar, al inicio del proceso aduanero, cuando se presenta la denuncia, las cuestiones relativas a la competencia cuantitativa ${ }^{[30]}$; o las relativas a la posibilidad de acumular causas, dadas las dificultades que presenta la referencia del instituto de fuente civil, el cual se relaciona con las «pretensiones» ( Código General del Proceso, 1989, art. 323.4 $\left.{ }^{[31]}\right)$. Asimismo, en su desarrollo, determinará la materia sobre cuales se circunscribirá la etapa probatoria, otorgando relevancia a la determinación de los hechos sobre los cuales se motiva la solicitud de iniciación del sumario por parte del Representante Fiscal, y que son prima facie fijados por el Juez al proceder a calificar jurídicamente los mismos (Código Aduanero de la República Oriental del Uruguay, 2014, art. 246, núm. 1). Ello garantiza el derecho de defensa, al circunscribir la prueba a la materia que es objeto de calificación prima facie.

Finalmente, con la Demanda Acusación Fiscal se ejercerá la acción y se determinará la pretensión. Con ella sí se fijará definitivamente el objeto del proceso aduanero.

\section{A MODO DE REFLEXIÓN NO CONCLUSIVA}

Como referimos inicialmente, el propósito del presente es poner sobre relieve algunas de las cuestiones que tradicionalmente se vienen afirmando de manera indiscutida en materia del Proceso judicial por infracciones aduaneras en el Uruguay, y repensar sin prejuicios sobre ello.

En su mérito, no podemos establecer a su término conclusiones definitivas al respecto. Por el contrario, solamente podemos esbozar algunas reflexionar sobre las mismas, que puedan permitir iniciar un estudio más amplio sobre el Proceso Aduanero Uruguayo.
La relevancia que ha adquirido el Derecho Aduanero actual, y la profundización en el estudio del mismo, viene determinando su incipiente autonomía.

Las particularidades de sus normas sustantivas tienen notable incidencia en el Proceso Aduanero, por ser éste dependientes de aquel.

El hecho de que el Proceso Aduanero es el ámbito donde se determine la ocurrencia o no de un hecho infraccional, y es el marco donde puede resultar la imposición de una sanción aduanera, remarca el carácter sancionatorio del mismo, lo cual impregna de modo determinante la forma en que se estructura el proceso, y que se aplican sus normas sustantivas, al igual que las adjetivas.

No comprender la asimetría de base entre el Proceso Aduanero y el Proceso Civil, puede determinar que se trasgredan el valor justicia y la garantía de la defensa en juicio a la que aludía Alais (2008).

Entendemos por ello que no se trata de realizar ligeros ajustes en función de las particularidades del Derecho Aduanero, sino que, por el contrario, se debe profundizar en su estudio, para con ello velar por la correcta aplicación de las normas legales o, incluso, su restructuración o fortalecimiento, llegado el caso.

Todo ello, será trascendente para una correcta aplicación de las normas infraccionales que tutelan bienes con relevancia jurídica, sin que ello implique, claro está, de modo alguno trasgredir derechos individuales, sino que por el contrario sean garantizados del mismo modo, en el marco del referido proceso.

[30] Véase que en el caso del Código Aduanero de la República Oriental del Uruguay, 2014, art. 228, que la «Determinación de la cuantía», se relaciona con la «imputación», no obstante el proceso se iniciará y sustanciará inicialmente a partir de la valoración en aduana realizada con la denuncia (Código Aduanero de la República Oriental del Uruguay, 2014, art. 225, o art. 241, núm. 1).

[31] Recuperado de: https://www.impo.com.uy/bases/codigo-general-proceso/15982-1988. 


\section{REFERENCIAS}

Alais, H. F. (2008). Los principios del Derecho Aduanero. Buenos Aires: Ed. Marcial Pons.

Basaldúa, R X. (1997). Introducción al Derecho Aduanero. Buenos Aires: Abeledo-Perrot.

Colombo, H. \& Torello, L. (1980). Procesos Jurisdiccionales Aduaneros. Montevideo: Ed. Idea.

Cotter, J. P. (2014). Derecho Aduanero. Tomos II. Ciudad Autónoma de Buenos Aires: Abeledo-Perrot.

Couture, E. J. (1964). Fundamentos del Derecho Procesal Civil. Buenos Aires: Ediciones Depalma.

Couture, E. J. (1983). Vocabulario jurídico: con especial referencia al derecho procesal positivo vigente uruguayo. Buenos Aires: Depalma. Segunda reimpresión.

Del Cueto, J. (1970). El contencioso Aduanero. Ubicación e Interpretación. Montevideo: Ed. Amalio M. Fernández.

Falcón Y Tella, M. J. \& Falcón Y Tella, F. Fundamento y finalidad de la sanción: ¿un derecho a castigar? Madrid: Marcial Pons.

García Vizcaino, C. (2010). Derecho Tributario. Derecho tributario formal, procesal y penal. Cuarta edición ampliada y actualizada. Buenos Aires: AbeledoPerrot.

González, A. D. (1946) Derecho Aduanero Uruguayo. Comentarios de la Legislación Represiva. Montevideo: Claudio García \& Cia - Editores.

Greif, Jaime. (1997). Manual de Derecho Procesal Penal. Montevideo: Fundación de Cultura Universitaria.

Labandera, P. (2016). «Estudios sobre el Código Aduanero de la ROU», en Código Aduanero de la República Oriental del Uruguay. Anotado y concordado. Segunda Edición. Ampliada y actualizada. Montevideo: Editorial La Ley Uruguay.
Llorens Fernandez, R. (1973). Tramitación del Represivo Aduanero. Montevideo.

Mazz, A. (2001), La integración económica y la tributación. Montevideo: Fundación de Cultura Universitaria.

Marabotto, J. \& ABAL, A. (1988). «Los procesos aduaneros», en Curso de Derecho Procesal, Tomo V, Vol. II, Instituto Uruguayo de Derecho Procesal. Montevideo: Fundación de Cultura Universitaria.

Palacio, L. (2001) Manual de Derecho Procesal Civil. Buenos Aires: Ed. Abeledo-Perrot.

Radovic Schoepen, A. (2010). Sistema sancionatorio tributario: infracciones y delitos. Santiago de Chile: Editorial Jurídica de Chile. Segunda Ed. actualizada.

Tarigo, E (1994). Lecciones de Derecho Procesal Civil. Tomo I. Montevideo: Fundación de Cultura Universitaria..

Torello, L., Marabotto, Jorge A., \& Simón, L. (1985). «La carga de la prueba, en el proceso aduanero», Jornadas de Derecho Procesal - 1985, Constitución y Proceso Penal - Proceso Aduanero. N. ${ }^{\circ}$ II. Montevideo: Fundación de Cultura Universitaria.

Varela, A. (2017) «Una necesidad imprescindible: Desterrar definitivamente el régimen de responsabilidad objetiva del infraccional aduanero». Revista IUS ET VERITAS N. ${ }^{\circ}$ 55. Lima: Asociación IUS ET VERITAS. pp. 236 y 254

\section{REFERENCIAS JURÍDICAS}

Código Aduanero N. ${ }^{\circ} 19276$ [Código] (2014). https://www.impo.com.uy/bases/codigoaduanero/19276-2014

Código de Organización de los Tribunales Civiles y de Hacienda [Ley N. ${ }^{\circ}$ 9164] (19 de diciembre de 1933). Montevideo: IMPO. https:// www.impo.com.uy/bases/leyes/9164-1933

Código de Procedimiento Civil [Ley N. ${ }^{\circ}$ 1379] (15 de noviembre de 1877). Montevi- 
deo: IMPO. https://www.impo.com.uy/ armandugon $/ 11 / 8$ ?carfin $=194$

Código General del Proceso N. 15982 [Código] (1988). https://www.impo.com.uy/bases/ codigo-general-proceso/15982-1988

Constitución de la República [Const] (28 de Junio de 1830). https://parlamento.gub.uy/documentosyleyes/constitucion
Ordenamiento financiero - se establecen normas dándose disposiciones sobre ingreso a la Administración Pública y se crea el Seguro de Salud para los funcionarios de la Administración de las Obras Sanitarias del Estado [Ley N. ${ }^{\circ}$ 13.318] (28 de diciembre de 1964). Montevideo: Parlamento del Uruguay. https://legislativo.parlamento.gub.uy/ temporales/leytemp6597868.htm 